\title{
Problemas enfrentados por terapeutas analítico-comportamentais em sua prática clínica
}

\section{Behavior analytic therapists' clinical practice problems}

\author{
Marina Gomes WIELEWICKI' \\ Jocelaine Martins da SILVEIRA ${ }^{2}$ \\ Carlos Eduardo COSTA ${ }^{3}$
}

\begin{abstract}
Resumo
O artigo apresenta situações-problema encontradas na interação com o cliente, conforme o relato de cinco terapeutas analistas comportamentais e algumas soluções adotadas. Os relatos foram obtidos por meio de uma entrevista, cujas verbalizações foram registradas e transcritas. As categorizações das verbalizações foram estabelecidas e ajustadas com a ajuda da avaliação de quatro colaboradores. Os resultados sugerem que situações de difícil manejo tendem a surgir quando o cliente: (a) aproxima-se do terapeuta de modo indevido, (b) contesta o terapeuta após feedback, (c) coloca sua vida ou a de terceiros em risco ou (d) provoca choro no terapeuta. Discute-se a importância do preparo dos profissionais para manejarem situações na interação com o cliente que, entre outras coisas, ameacem a privacidade do terapeuta ou que apelem para a exposição de questões pessoais do profissional. São sugeridas utilizações dos resultados para fins didáticos na formação de terapeutas comportamentais e para elaboração de pesquisas futuras.
\end{abstract}

Unitermos: interação entre terapeuta - paciente; psicoterapia, terapia analítico-comportamental; treino de terapeuta.

\begin{abstract}
The paper provides an identification of some problems faced by five behavior analytic therapists in their clinical practice, according to their reports and some solutions they have adopted. The therapists were interviewed and their verbalizations were registered and transcribed. Categories of those verbalizations were set and refined according to four judges. Results have indicated that some difficult situations tend to arise, mostly, when client: a) approaches therapist in an improper way; b) confronts therapist after receiving feedback; c) exposes his/her or someone elselife at risk; and d) makes therapist cry with his/her report. Some implications for therapist training and future research designs were discussed.
\end{abstract}

Uniterms: therapist patient interaction; psychotherapy; behavior analytical therapist; therapist trainees.

Constantemente, terapeutas se deparam com situações novas no contexto clínico. Algumas delas não chegam a constituir um desafio relevante para o repertório comportamental do profissional; outras, entretanto, além de inusitadas, são especiais por não encontrarem, no conjunto de habilidades do terapeuta, uma resposta eficaz para seu manejo.

WrV

- Mestranda em Análise do Comportamento, Universidade Estadual de Londrina. Londrina, PR, Brasil.

2 Universidade Federal do Paraná, Departamento de Psicologia, Setor de Ciências Humanas, Letras e Artes. Praça Santos Andrade, 50, Prédio Central, 10 andar, Sala 126, Centro, 80060-240, Curitiba, PR, Brasil. Correspondência para/Correspondence to: J.M. SILVEIRA. E-mail: <jocelainesilveira@pop.com.br>.

3 Universidade Estadual de Londrina, Departamento de Psicologia Geral e Análise do Comportamento, Centro de Ciências Biológicas. Londrina, PR, Brasil. 
Uma situação-problema, conforme concebida por Skinner (1953/1989), é aquela frente à qual "...o organismo não tem um comportamento imediatamente disponível que reduza a privação ou forneça um meio de fuga da estimulação aversiva" (p.238). Segundo Skinner, a situação-problema é particularmente caracterizada pela impossibilidade de emissão de uma resposta, o que, eventualmente, demanda uma estimulação discriminativa para determinar sua forma ou direção.

Tome-se o exemplo de um carro enguiçado. Essa situação é problemática se: "...nenhum comportamento que resulte na partida for disponível no momento e se o comportamento que anteriormente foi bem-sucedido ao dar partida for forte ou se tivermos outros indícios de o comportamento que depende do carro em funcionamento for forte"(Skinner, 1953/1989, p.238).

Logo "... a solução de um problema é simplesmente uma resposta que altera a situação de forma que a resposta com grande probabilidade de emissão possa ser emitida". No exemplo considerado, pôr gasolina no carro possibilitará o sucesso da resposta de acionar a ignição. Quando uma situação semelhante voltar a ocorrer, não será mais uma "situação-problema", já que "... a resposta que já tiver surgido como solução ocorrerá por ter sido reforçada em circunstâncias semelhantes" (Skinner, 1953/1989, p.239).

Skinner (1953/1989) prossegue analisando eventos que seriam apropriadamente chamados de "resolução" de um problema, distinguindo-os do surgimento fortuito de uma solução. Ou seja, nem sempre o aparecimento de uma solução equivale à resolução do problema. Uma solução acidental, por exemplo, poderá eliminar a situação-problema. Diversamente, resolver um problema implica manipular estímulos, arranjando-os ou rearranjando-os. Dar deixas, manipular níveis de privação e eliminar respostas que conflitem com a solução são exemplos de técnicas de resolução de problemas. O grau de dificuldade de um problema pode variar de fácil a insolúvel em razão da viabilidade de alteração das variáveis relacionadas ao surgimento da solução.

Ao longo de suas carreiras presume-se que o repertório comportamental dos terapeutas seja aprendido de tal forma que eles passem por cada vez 62 menos situações-problema, já que as situações para as quais uma resposta foi eficaz multiplicam-se paulatinamente.

A literatura sobre psicoterapia indica recorrentemente algumas condições do cliente delicadas para o manejo clínico. O trabalho com pacientes em risco de suicídio é talvez o exemplo mais típico. Por isso, nota-se um esforço em compartilhar na comunidade de psicoterapeutas recomendações quanto à avaliação do risco de suicídio, o levantamento de fatores de proteção, a preparação para tomadas de decisão e o preparo para intervenções de emergência (Meichenbaum, 2005). Outras condições do paciente que são freqüentemente discutidas é o uso abusivo de substâncias (Futterman, Lorente \& Silverman, 2005) ou ter sido vítima de abuso (Thomas, 2005).

Eventualmente, compara-se o comportamento ou características de terapeutas experientes e iniciantes durante as sessões de terapia, supondo que os primeiros apresentem habilidades a serem identificadas e ensinadas estrategicamente (Williams, Polster, Grizzard, Rockenbaugh \& Judge, 2003). A aliança terapêutica também tende a ser estudada com o intuito de antever dificuldades na condução e no resultado da terapia (Bedi, Davis \& Williams, 2005). Comparações entre estágios de treinamento em Psicologia Clínica também são documentadas presumindo que formas eficazes de treino habilitarão o terapeuta a lidar com situações complexas na clínica (O’Donovan, Bain \& Dyck, 2005).

Por fim, vale mencionar os artigos que focam a integração em psicoterapia. De certo modo, esses documentos auxiliam a identificação de intervenções comuns a diversas abordagens em psicoterapia diante de problemas clínicos usuais e de difícil tratamento, como a depressão (O'Connor, 2003).

Mayfield, Kardash e Kivlighan Jr. (1999), sugerem que terapeutas experientes são mais parcimoniosos nas descrições dos dados obtidos, são mais rápidos para detectar informações e para planejar tratamentos. Em contrapartida, os menos experientes tendem a focar a atenção em detalhes pouco relevantes e a realizar intervenções mais superficiais.

De acordo com a análise comportamental, uma formação educacional adequada é aquela que habilita o estudante a resolver problemas que surgirão remotamente no tempo. Guilhardi (1988) propôs que se 
rejeitasse a caracterização da análise do comportamento meramente pela aplicação de técnicas derivadas da sua análise experimental e indicou a primazia da análise funcional como ponto decisivo na identificação desse profissional. A habilidade de analisar funcionalmente o comportamento confere a versatilidade necessária ao profissional para solucionar problemas que possam surgir em situações clínicas remotas no tempo ou, de algum modo, distintas da atual.

Um exame da literatura brasileira indicou que os textos dirigidos à formação de terapeutas comportamentais enfocam habilidades básicas desses profissionais e abrangem um conjunto relativamente restrito delas (e.g., Marinho, Caballo \& Silveira, 2003; Rangé, Guilhardi, Kerbauy, Ingberman \& Falcone, 1998; Silvares \& Gongora, 1998; Silveira \& Silvares, 2003).

Pressupondo que exista uma gama mais ampla de situações relevantes nesse contexto, sua descrição poderá habilitar o profissional a manejá-las com êxito. Quando terapeutas se deparam com situações para as quais não têm uma resposta efetiva em seu repertório comportamental, isso se reflete, em maior ou menor grau, no tratamento psicológico oferecido.

Um modo de contribuir para a formação de terapeutas talvez seja possibilitar ao aprendiz o acesso a situações-problema e o modo como outros terapeutas lidaram com elas (Wielewicki, 2004). Nenhuma amostra de situações-problema poderá esgotar a miríade de possibilidades que um terapeuta pode, eventualmente, enfrentar no contexto clínico. Todavia, a categorização de algumas situações que possam ser problemáticas pode constituir um ponto de partida para discussões de problemas relacionados.

Portanto convém investigar quais são as situações-problema na interação entre terapeuta e cliente que os psicólogos comportamentais encontraram no contexto clínico e como as enfrentaram. 0 presente estudo visa identificar algumas situações-problema relatadas por terapeutas comportamentais na interação com alguns de seus clientes.

\section{Método}

\section{Participantes}

Foram entrevistadas cinco terapeutas comportamentais que atendiam há, pelo menos, cinco anos e, no mínimo, seis casos por semana. As terapeutas foram identificadas pelas letras A, B, C, D e E, conforme a ordem de participação no estudo. Todas são mulheres na faixa etária entre 30 e 55 anos (média de 41,5). O tempo de experiência clínica variou entre 7 e 30 anos de atendimento (Tabela 1). A seleção das participantes foi baseada nos critérios: a) tempo de experiência e número mínimo de atendimentos clínicos por semana, b) orientação teórica comportamental e c) acesso dos pesquisadores ao local de atuação.

\section{Instrumentos}

Foram usados, um gravador e fitas cassetes, e uma folha impressa com o modelo da entrevista a ser conduzida.

Os encontros com as participantes ocorreram nas respectivas clínicas ou instituições de ensino em que elas exerciam suas atividades profissionais.

\section{Procedimentos}

- Fase 1: Essa fase consistiu em entrevistar cinco terapeutas comportamentais, utilizando-se o seguinte roteiro: a) dados de Identificação; b) sexo; c) idade; d) ano de conclusão da graduação; e) tempo de atendimento; f) média de atendimentos por ano; g) local de atendimento: - clínica particular; - empresa; - instituição de ensino; - outros.

Você se lembra de alguma situação qualquer que tenha ocorrido na sua prática clínica, na interação com o cliente, para a qual você não tinha uma resposta eficaz em seu repertório (algo que fizesse você pensar: "Eu realmente não sei o que fazer")? Descreva-a.

Tabela 1. Tempo de atuação e média de atendimentos por semana de cada participante entrevistado na pesquisa.

\begin{tabular}{lcc}
\hline Participantes & Tempo de atuação & $\begin{array}{c}\text { Média de atendimentos } \\
\text { por semana }\end{array}$ \\
\hline A & 7 anos & 20 \\
B & 18 anos & 40 \\
C & 12 anos & 20 \\
D & 9 anos & 6 \\
E & 30 anos & 13 \\
\hline
\end{tabular}


As entrevistas foram registradas em fita cassete e, posteriormente, todos os registros foram transcritos ${ }^{4}$. Após uma semana da realização da entrevista, voltou-se a entrevistar a participante do estudo, que foi questionada sobre a ocorrência de alguma outra situação a acrescentar ao que havia dito na entrevista. As transcrições foram realizadas na íntegra e pela própria pesquisadora.

Durante o registro da entrevista com a participante "B", houve problemas na gravação e a entrevista foi repetida cerca de uma semana depois.

- Fase 2: as categorias de situações-problema indicadas nas entrevistas pelas terapeutas foram elaboradas a partir da leitura das transcrições. As categorias foram listadas e definidas em um quadro no qual se denominou para cada terapeuta uma letra, conforme a ordem em que foram entrevistadas (A, B, C, D ou E) e um algarismo arábico para cada situação relatada, conforme a ordem em que foram descritas.

- Fase 3: duas colaboradoras com formação em Psicologia graduadas há dois anos, com média de seis atendimentos por semana, foram convidadas a ler (independentemente uma da outra) as transcrições e o quadro em que as categorias foram listadas e descritas. Não houve treinamento para a realização dessa tarefa. As colaboradoras foram solicitadas a opinar sobre a pertinência da categorização, considerando as transcrições. Duas categorias que evocaram interpretações imprecisas pelas colaboradoras, que discordaram de suas definições, foram redefinidas. A categoria III, previamente denominada como "Cliente resistente à psicoterapia", foi redefinida para "Cliente descrente da psicoterapia" e a categoria VIII, inicialmente designada "Terapeuta não tem controle da situação", foi redefinida para"Intervenção em intervalo determinado na vida do cliente".

- Fase 4: outras duas colaboradoras, uma com formação em Psicologia, graduada há três anos, com média de oito atendimentos por semana, e outra graduanda do quinto ano de Psicologia receberam as transcrições e o quadro com as categorias já revisadas na Fase 3, e foram solicitadas a indicar o número de vezes em que as situações-problema referentes a cada categoria foram mencionadas. Essas outras duas colaboradoras também realizaram a tarefa independentemente uma da outra. Não houve treinamento para a realização da atividade, apenas uma descrição do trabalho a ser feito. Comparando o número indicado por cada colaboradora, das 20 situações relatadas, houve discordância em duas delas, portanto o índice de acordo foi de 90\%. Uma colaboradora julgou que a situação-problema 2, citada pela terapeuta "E" (E 2), poderia pertencer tanto à categoria II "Cliente contesta verbalmente o terapeuta após feedback", como à categoria III "Cliente descrente da psicoterapia". A situação-problema foi mantida na categoria III, já que foi uma das opções dessa colaboradora e não foi questionada pela outra colaboradora. A outra colaboradora julgou que a situação-problema 5, citada pela terapeuta "A" (A 5), poderia pertencer à categoria II "Cliente contesta verbalmente terapeuta após feedback" ou à categoria IV "Cliente pondo sua própria vida em risco ou a de terceiros". Como no caso anterior, a situação-problema foi mantida na categoria IV, já que foi uma das opções dessa colaboradora e não foi questionada pela outra colaboradora.

\section{Resultados e Discussão}

As categorias I e V apresentadas na Tabela 2 indicam que situações de difícil manejo tendem a surgir quando questões pessoais do terapeuta emergem na interação com o cliente, conforme relatado pelas próprias terapeutas nas entrevistas. Das 20 situações-problema relatadas, seis estão contidas nessas duas categorias. Isso chama a atenção para a importância do preparo formal de terapeutas para o manejo de situações em que aspectos de sua privacidade são abordados pelo cliente. A categoria II sugere que outro tipo de situação de difícil manejo emerge quando o cliente, de alguma maneira, parece questionar o desempenho profissional do terapeuta. As duas terapeutas com menor tempo de experiência (A e D, ver Tabela 1) foram as que relataram esse tipo de situação. Talvez terapeutas menos experientes tenham maior probabilidade de fornecer um feedback inadequado; talvez o cliente fosse contestador por estar sendo atendido por terapeutas jovens. Não é possível saber

$64 \quad{ }^{4}$ As transcrições constam em Wielewicki (2004). 
Tabela 2. Numeração e definição das categorias elaboradas com base nas transcrições das entrevistas.

\begin{tabular}{|c|c|c|}
\hline Numeração & Categoria & Descrição \\
\hline I & Cliente aproxima-se do terapeuta de modo indevido & $\begin{array}{l}\text { Cliente apaixona-se pelo terapeuta, ou apresenta comportamentos } \\
\text { imitativos exacerbados, ou apresenta risco de conduta imprópria na } \\
\text { sessão (possibilidade de exibição de órgão genital) (A 1; C 2; D 5) }\end{array}$ \\
\hline$\|$ & $\begin{array}{l}\text { Cliente contesta verbalmente o terapeuta após } \\
\text { feedback }\end{array}$ & $\begin{array}{l}\text { Cliente discorda dos apontamentos do terapeuta, contestando-o (A } \\
2 ; \mathrm{A} 3 ; \mathrm{A} 4 ; \mathrm{D} 3 ; \mathrm{D} 4)\end{array}$ \\
\hline III & Cliente descrente da psicoterapia & $\begin{array}{l}\text { Cliente em sofrimento, mas sentindo-se contrariada em procurar ajuda } \\
\text { psicoterapêutica, afirmando não acreditar em Psicologia (E 2) }\end{array}$ \\
\hline IV & $\begin{array}{l}\text { Cliente pondo sua própria vida em risco ou a de } \\
\text { terceiros }\end{array}$ & $\begin{array}{l}\text { Cliente corre risco de morrer ou emite comportamentos que ameaçam } \\
\text { a vida de terceiros }(A 5 ; B 3 ; D 7)\end{array}$ \\
\hline V & Cliente provoca choro no terapeuta com seu relato & $\begin{array}{l}\text { Terapeuta emociona-se intensamente com relato do cliente (B 1; B 2; } \\
\text { C 3) }\end{array}$ \\
\hline VI & Cliente chora copiosamente na sessão & $\begin{array}{l}\text { Cliente apresenta choro intenso e ininterrupto na sessão, dificultando } \\
\text { qualquer intervenção (D 1) }\end{array}$ \\
\hline VII & Cliente relata ter sofrido abuso sexual & $\begin{array}{l}\text { Cliente relata ter sido abusada sexualmente na infância por um familiar } \\
\text { (D 2) }\end{array}$ \\
\hline VIII & $\begin{array}{l}\text { Intervenção em intervalo determinado na vida do } \\
\text { cliente }\end{array}$ & $\begin{array}{l}\text { Cliente grávida de oito meses com queixa de síndrome do pânico ou } \\
\text { cliente aguardando um provável diagnóstico de doença grave (D 6; } \\
\text { C 1) }\end{array}$ \\
\hline IX & Cliente não apresenta condições de cuidar-se & Cliente que apresenta depressão severa (E 1) \\
\hline
\end{tabular}

exatamente os fatores que conduziram à situação relatada. De qualquer modo, independentemente da adequação do feedback fornecido pelas terapeutas, o ponto importante foi a falta de repertório delas para lidarem com a situação da contestação por parte do cliente, seja reconhecendo a própria inadequação da intervenção, seja levantando com o cliente outros motivos para a contestação.

Nota-se que a categoria I (Tabela 3) "cliente aproxima-se do terapeuta de modo indevido" foi

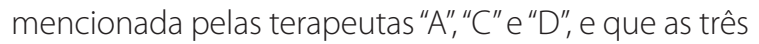
profissionais foram surpreendidas com situações diversas. A primeira mencionou um caso em que o cliente se apaixonou por ela, a terapeuta "C" relatou o caso de um cliente com queixa de comportamentos de exibição dos genitais e a terapeuta "D", de uma cliente que passou a imitá-la. De qualquer modo, o que parece relevante nesses relatos é a dificuldade das terapeutas para manejar algum tipo de aproximação indevida do cliente, que Ihes cause desconforto. Nesse ponto, talvez caiba pensar na pertinência do treino de terapeutas para a tarefa de inibirem aproximações do cliente que lhes causem desconforto. Outras categorias mencionadas com freqüência foram a ll"cliente contesta verbalmente o terapeuta após feedback"; a IV “cliente pondo a própria
Tabela 3. Número de situações relatadas por terapeuta e categorias relacionadas.

\begin{tabular}{lcccccccccc}
\hline & \multirow{2}{*}{$\begin{array}{c}\text { Situação } \\
\text { Tempeuta }\end{array}$} & \multicolumn{1}{c}{ Categorias } \\
\cline { 3 - 11 } & relatadas (n) & I & II & III & IV & V & VI & VII & VIII & IX \\
\hline A & 5 & 1 & 3 & & 1 & & & & & \\
B & 3 & & & & 1 & 2 & & & & \\
C & 3 & 1 & & & & 1 & & & 1 & \\
D & 7 & 1 & 2 & & 1 & & 1 & 1 & 1 & \\
E & 2 & & & 1 & & & & & & 1 \\
\hline Total & 20 & 3 & 5 & 1 & 3 & 3 & 1 & 1 & 2 & 1 \\
\hline
\end{tabular}

vida em risco ou a de terceiros" e a V "cliente provoca choro no terapeuta com seu relato".

Um dado interessante na Tabela 3 é o número de situações relatadas pelas terapeutas. As com menor tempo de experiência (A e D) relataram um maior número de situações-problema do que a com maior tempo de experiência (E). Algumas razões pelas quais terapeutas com menor tempo de experiência têm mais facilidade em relatar os problemas que enfrentaram durante o exercício profissional podem ser: (a) a falta de repertório no início da carreira é maior do que quando já se acumularam muitos anos de profissão; (b) é mais fácil relatar casos mais recentes - terapeutas experientes podem ter enfrentado diversas situações-problema no 
início da carreira que não são mais capazes de relatar. Essas alternativas não são mutuamente excludentes. Pesquisas futuras nessa linha deveriam levar em consideração o fato de que entrevistas com terapeutas menos experientes possam ser mais ricas em relatos de situações-problema.

As soluções encontradas pelas profissionais em cada uma das categorias indicam as soluções encontradas pelas terapeutas "A"," $C$ "e "D" para a situação-problema em que o cliente aproxima-se de modo indevido do terapeuta.

As soluções encontradas foram diferentes, de acordo com a situação específica enfrentada. A solução encontrada pela terapeuta " $A$ " foi encaminhar o cliente que se declarou apaixonado por ela. A profissional " $\mathrm{C}$ ", que relatou dificuldades na interação com um cliente com queixa de exibicionismo, estabeleceu um contato mais formal com o cliente. A terapeuta "D"falou à cliente que havia notado que ela a estava imitando e discutiu o assunto. Caso se busque um denominador comum das soluções encontradas, aparentemente, elas são de dois tipos: ou o terapeuta distancia-se deliberadamente do cliente, ou explicita seu desconforto, tornando-o consciente para o cliente.

Procedimentos diversos também ocorreram diante da situação-problema em que o cliente agride verbalmente o terapeuta após um feedback. A terapeuta "D" explicou a análise, sendo empática com o cliente; a terapeuta A, relatou ter aplicado os procedimentos da Psicoterapia Analítico-funcional na sessão.

Aparentemente, nesse caso, a natureza do problema do cliente definiu o tipo de solução frente à agressão. De qualquer modo, ignorar a confrontação do cliente foi um procedimento comum adotado tanto pela terapeuta "A" quanto pela "D".

A categoria III refere-se às situações-problema em que o cliente manifestou descrédito em relação à psicoterapia. A solução encontrada para essa situação pela terapeuta "E" foi a de não reforçar esse comportamento do cliente, atentando para outros elementos relevantes do processo terapêutico.

Nos casos em que o cliente ameaçava sua própria vida ou a de terceiros, as profissionais " $A$ " e "B" adotaram a conduta de alertar a família sobre o risco, 66 tomando o cuidado de discutir antes o procedimento com o cliente a fim de manter o vínculo terapêutico. A terapeuta "D", no entanto, procedeu de forma a manter-se à disposição da cliente para que Ihe telefonasse no momento em que estivesse nessas situações. Na referida categoria de situação-problema, participar a família dos riscos detectados foi uma solução adotada por duas das três terapeutas.

Quanto às soluções encontradas pelas terapeutas nas situações-problema em que o relato do cliente provoca choro, as terapeutas "B" " $^{2}$ ", que relataram as situações dessa categoria, adotaram procedimentos distintos nesse aspecto. A profissional "B", que relatou dois casos dessa categoria, procedeu de forma a mostrar a emoção ao cliente, sem esconder ou conter o choro, falou de suas emoções para ele. Já a terapeuta "C" adotou o procedimento de evitar que o cliente percebesse sua emoção.

Possivelmente, a discrepância na resolução desse problema esteja relacionada à natureza do caso ou do cliente. A profissional "B" interagia com clientes adultos, enquanto a terapeuta "C"relatou o caso de uma criança. Enquanto o choro do terapeuta pudesse sinalizar proximidade e empatia para o cliente adulto, para aquela criança talvez sugerisse que o que ela relatara era grave demais. Portanto as soluções do problema referentes a essa categoria pareceram guiadas por certas características do cliente.

A terapeuta "D" não relatou o procedimento adotado diante da situação-problema em que o cliente chora copiosamente na sessão. No entanto a terapeuta relatou que em outras situações consideradas "problemáticas", como quando o cliente revela ter sido abusado sexualmente, optou por falar abertamente sobre o abuso em vez de ignorá-lo.

Na categoria da situação-problema"Intervenção em intervalo determinado na vida do cliente", as profissionais " $C$ " $\mathrm{e}$ " $\mathrm{D}$ " relataram a dificuldade de adotar um procedimento em um intervalo curto de tempo, dada à situação do cliente. A terapeuta " $C$ " relatou dificuldade ao precisar intervir em um período em que sua cliente aguardava o resultado de um exame anti-HIV. A terapeuta afirmou que sua dificuldade advinha do fato de saber que não poderia desamparar a cliente, mas pessoalmente ainda não se sentia preparada para ajudá-la a aceitar e conviver com o diagnóstico da síndrome. A terapeuta relatou ter tentado acalmar a 
cliente, mas não descreveu como procurou fazer isso. A terapeuta " $D$ " relatou ter sido difícil para ela intervir no caso de uma cliente gestante com crises de pânico. A profissional manteve-se à disposição da cliente para acompanhá-la no momento do parto, mas não iniciou a intervenção usual no tratamento de pânico por julgar que resultados positivos seriam improváveis em um período tão curto.

A terapeuta "E" relatou uma situação-problema em que a cliente, em razão de uma depressão severa, não apresentava condições de cuidar-se, ou seja, não fazia a higiene pessoal, não se alimentava, etc. A terapeuta elegeu uma cunhada da cliente para atuar como acompanhante terapêutico, auxiliando-a nas tarefas da vida diária, até que a cliente apresentasse condições de fazê-lo sozinha. Portanto, de modo semelhante a uma das soluções encontradas para a categoria IV (quando há ameaça à vida do cliente ou de terceiros), a solução para a categoria $\vee$ "cliente não apresenta condições de cuidar-se" foi apelar para uma rede de apoio, recorrendo a familiares.

\section{Considerações Finais}

Situações-problema eventualmente ocorrerão na prática do psicólogo clínico. É possível que o treino de repertórios comportamentais versáteis na formação profissional ajude a manejar alguns eventos surpreendentes sem que se constituam situações-problema insolúveis.

O objetivo central desse estudo foi relatar situações difíceis para terapeutas de modo que, quando outras semelhantes ocorrerem, algumas soluções possam ter sido cogitadas por clínicos que leram os resultados e discussão. Para pesquisadores, o estudo indica que é possível categorizar, isto é, organizar eventos críticos que surpreendem terapeutas no contexto clínico. Aqui foram identificadas nove situações importantes. Resumidamente, os resultados e discussão indicaram alguns pontos:

a) Situações que envolvem assuntos pessoais do terapeuta foram consideradas difíceis pelos profissionais que participaram do estudo.

b) Quando a situação-problema se relacionava com a aproximação indevida do cliente, os terapeutas tenderam a distanciar-se, encaminhando o caso ou estabelecendo certo grau de formalidade.

c) Quando o cliente agrediu verbalmente o terapeuta após um feedback, ignorar a agressão foi um procedimento adotado.

d) Havendo ameaça à vida do cliente ou de terceiros, os terapeutas optaram por comunicar o fato à família.

e) Quando o relato do cliente produziu choro na terapeuta, os procedimentos pareceram basear-se no critério do quanto a auto-exposição do terapeuta seria salutar para o cliente.

f) Diante da impossibilidade de intervir em um período extremamente curto, as terapeutas tenderam a, pelo menos, apoiar o cliente, dispondo-se a acompanhá-lo em momentos difíceis.

g) Finalmente, quando o problema consistiu na incapacidade do cliente de cuidar-se, o procedimento adotado foi envolver familiares no tratamento.

A consulta à literatura sobre psicoterapia indica que muitas das situações de difícil manejo na clínica requerem intervenções emergenciais por parte do terapeuta, as quais, muitas vezes, são atípicas. O manejo de risco de suicídio, da exposição da própria vida do paciente ou de outras pessoas, assim como do uso abusivo de substâncias pode requerer o envolvimento de agências, ou de pessoas que costumeiramente não participam em tratamentos psicológicos convencionais (Futterman, Lorente, \& Silverman, 2005; Meichenbaum, 2005; O'Connor, 2003; Thomas, 2005). A identificação de eventos ambientais que se constituem fatores de proteção para a ocorrência de eventos indesejáveis ao paciente é também uma medida comumente adotada pelos clínicos nas situações de difícil manejo.

As idéias acima indicam algumas possibilidades de solução para diversas situações-problema enfrentadas por terapeutas. Todavia não devem ser encaradas como "procedimentos-padrão" a serem adotados sem outras considerações levantadas a partir de uma análise funcional do caso. Foge ao escopo do presente trabalho uma avaliação da adequação dos procedimentos adotados pelas terapeutas. A avaliação dessa adequação, como apontado anteriormente, envolveria uma análise funcional dos casos atendidos. Resta saber se situações-problema semelhantes seriam relatadas por outras 
amostras de terapeutas também comportamentais, por terapeutas de orientação teórica diferente, terapeutas do sexo masculino ou terapeutas que atendam a populações específicas (crianças, adolescentes, adultos, casais ou usuários de substâncias de abuso, etc.). Com relação às perguntas feitas aos terapeutas do presente estudo, talvez fosse interessante perguntar também em que época da carreira do terapeuta ocorreu a situação-problema.

Os resultados do presente estudo indicam que pode ser bem-vinda a elaboração de manuais de preparação que descrevam para os clínicos, situações consideradas incomuns ou difíceis e formas de manejá-las. As situações aqui descritas poderiam também ser discutidas ou simuladas (por meio de role-playing) em supervisões ou disciplinas de prática clínica em cursos de graduação. Uma avaliação se tal procedimento melhoraria o desempenho de um terapeuta em outras situações-problema e em relação a terapeutas que não tenham sido submetidos a esse procedimento poderia indicar melhor a importância e a direção de estudos futuros sobre esse assunto.

\section{Referências}

Bedi, R. P., Davis, M. D., \& Williams, M. (2005). Critical incidents in the formation of ther therapeutic alliance from the clients perspective. Psychotherapy: Theory, Research, Practice, Training, 42 (3), 311-323.

Futterman, R., Lorente, M., \& Silverman, S. W. (2005). Beyond harm reduction: a new model of substance abuse treatment further integrating psychological techniques. Journal of Psychotherapy Integration, 15 (1), 3-18.

Guilhardi, H. J. (1988). A formação do terapeuta comportamental. Que formação? In H. W. Lettner \& B. P. Rangé (Orgs.), Manual de psicoterapia comportamental (pp.313-320). São Paulo: Manole.

Mayfield, W. A., Kardash, C. M., \& Kivlighan Jr, D. M. (1999). Differences in experienced and novice counselors' knowledge structures about clients: implications for case conceptualization. Journal of Counseling Psychology, $46,504-514$.
Marinho, M. L., Caballo, V., \& Silveira, J. M. (2003). Cuestiones olvidadas en la Terapia Conductual: las habilidades del terapeuta. Psicologia Conductual, 11 (1), 135-161.

Meichenbaum, D. (2005). 35 years of working with suicidal patients: lessions learned. Canadian Psychology, 46 (2), 64-72.

O'Connor, R. (2003). An integrative approach to treatment of depression. Journal of Psychotherapy Integration, 13 (2), 130-170.

O'Donovan, A., Bain, J. D., \& Dyck, M. J. (2005). Does clinical psychology education enhance the clinical competence or practioners? Professional Psychology: Research and Practice, 36 (1), 104-111.

Rangé, B., Guilhardi, H., Kerbauy, R., Ingberman, Y., \& Falcone, E. (1998). Ensino, treinamento, e formação em psicoterapia comportamental cognitiva. In B. Rangé (Org.), Psicoterapia comportamentale cognitiva: pesquisa, prática, aplicações e problemas (pp.331-351). Campinas: Editorial Psyll.

Silvares, E. F. M., \& Gongora, M. A. N. (1998). Psicologia clínica e comportamental: a inserção da entrevista com adultos e crianças. São Paulo: Edicon.

Silveira, J. M., \& Silvares, E. F. M. (2003). Condução de atividades lúdicas no contexto terapêutico: um programa de treino de terapeutas comportamentais infantis. In M. Z. S. Brandão, F. C. S. Conte, F. S. Brandão, Y. K. Ingberman, C. B. Moura, V. M. Silva \& S. M. Oliane (Orgs.), Sobre comportamento e cognição: a história eos avanços, a seleção por conseqüências em ação (Vol.11, pp.272-281). Santo André: ESETec Editores Associados.

Skinner, B. F. (1989). Ciência e comportamento humano. São Paulo: Martins Fontes (Originalmente publicado em 1953).

Thomas, P. M. (2005). Dissociation and internal models of protection: psychothrapy with child abuse survivors. Psychotherapy: Theory, Research, Practice, Training, 42 (1), 20-36.

Wielewicki, M. G. (2004). Situações-problema encontradas porterapeutas comportamentais na interação com o cliente. Monografia não-publicada, Universidade Estadual de Londrina.

Williams, E. N., Polster, D., Grizzard, M. B., Rockenbaugh, J., \& Judge, A. B. (2003). What happens when therapists feel bored or anxious? a qualitative study of distracting self-awareness and therapist's management strategies. Journal of Contemporary Psychotherapy, 33 (1), 5-18.

Recebido em: 27/9/2004

Versão final reapresentada em: 30/6/2006

Aprovado em: 5/9/2006 